\title{
A utilização do RPG "Epidemia" como estratégia metodológica para o ensino de Ciências e Geografia no Ensino Fundamental a partir de uma perspectiva CTS
}

\author{
The use of the rpg "epidemia" as a methodological strategy for teaching \\ sciences and geography in fundamental teaching from a sts perspective.
}

\author{
José Renato Pereira Brasil (renato.itau@ hotmail.com) \\ Mestrando em ensino. Universidade do Estado do Rio Grande do Norte - UERN
}

Albino Oliveira Nunes (albino.nunes@ifrn.edu.br)
Instituto Federal de Educação, Ciência e Tecnologia do Rio Grande do Norte- IFRN

Jucieude de Lucena Evangelista (jucieudelucena@ hotmail.com) Universidade do Estado do Rio Grande do Norte - UERN

Luiz Carlos Aires Macedo ( luizcarlos@ufersa.edu.br)

Universidade Rural do Semi-Árido - UFERSA

Resumo: O presente artigo tem como objetivo realizar uma breve exposição teórica sobre a perspectiva Ciência, Tecnologia e Sociedade-CTS na educação e propor a utilização do Role Playing Game-RPG "EPIDEMIA” como estratégia metodológica para o ensino de ciências e geografia a partir de uma concepção CTS. O texto está estruturado em quatro partes distintas. A primeira parte do texto é um breve relato sobre o desenvolvimento do movimento CTS no mundo destacando as suas concepções acerca da importância da C\&T para sociedade bem como as implicações para a sociedade. Depois traçamos um breve relato sobre o movimento CTS no Brasil e seus desdobramentos no ensino de Ciências. Na terceira parte apresentamos um breve relato sobre Role Playing Game-RGP; em seguida temos o RPG "EPIDEMIA" e a sequência didática de como utilizá-lo em sala de aula. Por fim, concluímos que a nossa proposta metodológica baseado na utilização do RPG "EPIDEMIA" como suporte para as discussões no processo de ensino e aprendizagem de Ciências e Geografia com enfoque CTS, apresenta um grande potencial a ser explorado na sala de aula.

Palavras-Chave: Estratégia metodológica; Sequência didática; Role Playing Game.

Abstract: This article aims to make a brief theoretical presentation on the Science, Technology and Society-CTS perspective in education and to propose the use of the RPG "EPIDEMIA" as a methodological strategy for teaching science and geography from a CTS conception. The text is structured in four distinct parts. The first part of the text is a brief account of the development of the CTS movement in the world, highlighting its conceptions about the importance of S\&T for society as well as the implications for society. Then we trace a brief account of the CTS movement in Brazil and its developments in science education. In the third part we present a brief account of Role Playing Game-RGP; next we have the RPG "EPIDEMIA" and the didactic sequence of how to use it in the classroom. Finally, we conclude that our

Recebido em: $1 \% 04 / 2020$

Aceito em: 15/09/2020 
methodological proposal based on the use of the RPG "EPIDEMIA" as a support for discussions in the teaching and learning process of Science and Geography with a CTS focus, has great potential to be explored in the classroom.

Keywords: Methodological strategy; Didactic sequence; Role Playing Game.

\section{INTRODUÇÃO}

Um dos maiores desafios que temos de enfrentar no ensino de Ciências e Geografia é aproximar os educandos e os conteúdos programáticos a realidade que eles estão inseridos. Mediante a essa constatação real e concreta, se faz necessário, conduzir o processo de ensino e aprendizagem a partir de uma perspectiva emancipatória e crítica e que esse ensejo esteja no cerne do processo educativo. Vale salientar que o processo de ensino e aprendizagem veem passando por inúmeras transformações nas últimas décadas, ocasionado principalmente pelo advento dos meios de comunicação em massa como por exemplo a internet, devido a carga e sobrecarga de informação que os discentes estão submetidos, o ensino tradicional e mnemônico não é mais capaz de oferecer aos discentes respostas plausíveis para as indagações que surgem no dia a dia.

Neste âmbito é necessário o desenvolvimento e a implementação de estratégias de ensino que tenha como foco a formação de sujeitos que estejam inteirados com a realidade ao qual estão inseridos e que visualizem na educação, na ciência e na tecnologia os elementos necessários para transformar a realidade a sua volta, tornandose cidadãos críticos e atuantes no espaço social em que convivem.

Mediante a esse desvelamento, o presente texto tem a finalidade de propor o uso do Role Playing Games -RPG como estratégia metodológica para o ensino de Ciências e Geografia baseado no movimento Ciências, Tecnologia e Sociedade - CTS, para tanto, utilizaremos o RPG "Epidemia” de autoria do professor Amaral (2013) como suporte para o desenvolvimento das discussões no ensino de Ciências e Geografia, bem como tornar as aulas mais dinâmicas e permitir aos educandos um melhor entendimento de conceitos fundamentais para a compreensão do papel da ciência e tecnologia na/para sociedade.

O texto está estruturado em quatro partes, sendo que a primeira parte fizemos um breve relato sobre o desenvolvimento do movimento CTS, depois destacamos como esse movimento foi desenvolvido e implementado no Brasil; a terceira, apresenta uma descrição sucinta do que é o Role Playng Game-RPG, bem como seu potencial 
pedagógico; por último, apresentaremos o RPG “epidemia" e uma sequência didática de como utilizá-lo de maneira interdisciplinar no ensino de Ciências e Geografia.

Por fim, traçamos nossas considerações, na qual destacamos a importância de novas abordagens metodológicas em sala de aula com o intuito de tornar o processo de ensino e aprendizagem significativo e emancipatório, permitindo aos educandos desenvolver a sua capacidade de pensamento crítico, pois como sabemos os educandos têm o direito à um ensino de qualidade e desafiador centrado na construção de saberes e na busca por elementos que possibilite a sua própria constituição enquanto cidadão.

\section{O MOVIMENTO CTS:}

O movimento CTS surgiu a partir da segunda metade do século XX em países como Estados Unidos, Inglaterra, Canadá e Holanda, etc, sendo que ganhou maior destaque no cenário mundial a partir dos estudos de Thomas Kuhn, A estrutura das revoluções científicas e o trabalho da Rachel Carsons, Silente Spring (Primavera Silenciosa), ambos na década de 1960 (AULER; BAZZO, 2001). O movimento CTS tem como objetivo fazer uma discussão e reflexão acerca do papel da ciência e tecnologia no nosso dia a dia, desvelando qual o papel que ambos têm na sociedade. Para tanto, é preciso romper com a visão romântica que temos sobre Ciência e Tecnologia - C\&T como responsável por todos os benefícios presentes na sociedade Bazzo (2014). Já Santos (2007, p. 06) destaca que:

"Esse mito cientificista tem influenciado drasticamente o nosso modo de vida, de forma que o nosso comportamento muitas vezes segue mais a lógica da razão científica, do que propriamente razões de natureza humana como emocionais, afetivas, estéticas etc."

Neste sentido, se faz necessário romper com essa lógica que está presente na nossa sociedade e abrir espaço para outras vertentes e formas de pensamento, a fim de contribuir para o entendimento mais amplo e complexo dos diferentes elementos que compõem a sociedade. Desta forma, o movimento CTS designa diferentes formas de pensamento contra hegemônicas sobre a ciência e a tecnologia, oriundas da relação problemática que a sociedade mantinha (ou mantém) sobre o entendimento e financiamento de C\&T (MEMBIELA, 2001; CEREZO, 1998).

Porém, como já sinalizado não existe apenas um movimento CTS, senão linhas de pesquisa/atuação que apresentam fundamentos comuns. Tradicionalmente se aponta a existência de duas linhas: 1) uma europeia, mais ligadas aos antecedentes da ciência e

Recebido em: $1 \% 04 / 2020$

Aceito em: 15/09/2020 
tecnologia e 2) uma norte americana, mais ligada às consequências socioambientais daquelas. (GARCÍA, LÓPEZ CEREZO e LUJÁN LOPEZ, 1996). Há que se pontuar, no entanto, que existe uma terceira linha de pensamento em CTS, o Pensamento LatinoAmericano em Ciência, Tecnologia e Sociedade (PLACTS) que sempre esteve muito interessado sobre questões de política científica e o desenvolvimento dos países periféricos (STRIEDER, 2012).

Outro fato que merece destaque é a visão errônea que se tem em relação a C\&T, pois o que se veicula na mídia é a ideia de que ao passo que se amplia o desenvolvimento científico-tecnológico, necessariamente mais desenvolvimento social, , passando a impressão de que a medida que se avança na ciência todos os outros setores se desenvolvem juntos com a mesma velocidade e eficácia, todavia Auler e Bazzo (2001) revelam que essa ideia está equivocada, haja vista, que em muitos casos o desenvolvimento científico e tecnológico nem sempre se transformam em benefícios para usufruto de todos os membros da sociedade.

É preciso elucidar qual o papel que a C\&T realmente tem na sociedade e quais os atores e discursos são transmitidos e veiculados na mídia acerca desta questão, mediante a essas indagações surge o movimento CTS que vem indagar qual realmente é o papel da C\&T para a sociedade.

Os ideais defendidos pelo movimento CTS tem como princípio norteador realizar debates e trazer discussões sobre C\&T para o campo político e econômico, afim de desvelar as consequências negativas ocasionados na sociedade (AULER; BAZZO, 2001). Com base nas colocações expostas fica nítido que o processo de ensino e aprendizagem em ciências com base em uma perspectiva CTS desempenha um papel importantíssimo para a nossa sociedade, pois tem como função trazer à tona os verdadeiros propósitos da C\&T, além de reivindicar decisões mais democráticas e menos tecnocratas (AULER, 2007).

Nesse sentido que é que desde o seu início a educação tem sido um dos principais focos de atuação do movimento, dando origem ao que se denomina enfoque CTS no ensino. Esse enfoque pode ser inserido na educação formal de diversas formas, desde o CTS como mero elemento motivador para aprender ciência até o estudo das relações CTS sem o aprofundamento científico (SANTOS e MOTIMER, 2000). Porém, Rosa e Strieder (2018) alertam para a existência de lacunas em grande parte dos trabalhos educativos com a perspectiva CTS sobre a reflexão da democratização dos processos 
decisórios sobre C\&T. Nota-se, ainda, que apesar de diversas iniciativas na produção de materiais didáticos e formulação de currículos ao redor do mundo, que o Brasil carece de propostas de materiais didáticos para se trabalhar com o enfoque CTS (NUNES, 2014), especialmente em algumas disciplinas específicas de nível superior (NUNES et al., 2020).

Levando em consideração essas questões, a sala de aula é o espaço ideal para realizar este debate, tendo em vista que o professor ao trabalhar essas demandas permite ao aluno quebrar esses obstáculos enraizados na cultura popular e essa visão restrita e linear do que é C\&T. Neste âmbito os alunos terão a oportunidade de construir um conhecimento mais amplo rompendo com a visão romântica e histórica de que a ciência é sinônimo de desenvolvimento ao mesmo tempo irão perceber que a visão sobre ciência e tecnologia que é transmitida pela mídia e cultura de massa é fruto de uma dominação socioeconômica imposta pela classe dominante.

Nos países subdesenvolvidos essa linha de pensamento que defende a visão de que a C\&T é responsável pelo desenvolvimento incondicional do país, esse raciocínio também é compartilhado no Brasil, no qual credita a ciência e a tecnologia como a único meio pelo qual o país pode tornar-se desenvolvido. Deste modo a educação brasileira precisa de maneira urgente buscar um forma de debate a temática em foco, com o intuito de demonstrar a conjuntura atual que o país vivencia em relação ao entendimento sobre C\&T e fazer uma contextualização demonstrando que existe outras visões acerca do que é ciência, todavia para que isso se concretize é fundamental um processo educativo principalmente no ensino de ciências pautado nos postulados CTS e que tenha como meta e enfoque o ser o humano e as questões socioambientais.

\section{O MOVIMENTO CTS NO BRASIL E SEUS DESDOBRAMENTO NA EDUCAÇÃO.}

As discussões sobre o movimento CTS na educação brasileira tiveram início sobretudo nas décadas de 1950 e 1980 com a inovação dos currículos no ensino de ciências, sendo que em um primeiro momento tais discursões giraram em torno de questões políticas. Foi sobretudo nos anos 1980 que os currículos de ciências passaram a dar ênfase maior as discussões sobre desenvolvimento científico e tecnológico (KRASILCHIK,1987, apud SANTOS E MORTIMER, 2000). 
Já nos anos 1990, podemos citar a importância da "Conferência Internacional de Ciências para o século XXI: ACT-Alfabetização em Ciências e Tecnologia” (SANTOS E MORTIMER, 2000); sendo que essa conferência foi fundamental, pois fortaleceu as bases para discussão sobre o ensino de ciências no país levando em consideração o enfoque CTS.

Apesar das discussões sobre o ensino de ciências baseados no movimento CTS no país, este necessita ganhar maior visibilidade e corporeidade para poder cumprir com o seu papel formativo e esclarecer aos alunos de modo geral a importância de compreender a função da C\&T. Diferentemente do que aconteceu em outros países, no Brasil não tivemos um movimento CTS organizado e sistematizado forte, o que observamos foi a ocorrência de iniciativas isoladas que obtiveram relativo êxito (BERNARDO, VIANNA e SILVA, 2001). É importante salientar o desenvolvimento dos currículos oficiais do ensino de ciências que passaram a ter um foco CTS. Ao inserir as discussões CTS nos currículos do ensino de ciências, esta passou a ser abordada e entendida de maneira mais ampla, permitindo melhor entendimento acerca dos conceitos científicos; esse conjunto de ideias são defendidos por Santos e Mortimer (2000) que destacam o seguinte:

[...] os conteúdos dos currículos CTS apresentam uma abordagem de ciência em sua dimensão ampla, em que são discutidos muitos outros aspectos além da natureza da investigação científica e do significado dos conceitos científicos. (SANTOS e MORTIMER ,2000, p.116117).

Ao analisarmos essa constatação fica nítido que o cenário atual é promissor para o crescimento dos postulados CTS, todavia mudanças ainda são necessárias para implementarmos processos decisórios e críticos frente as questões científicas e socioambientais que nos assolam. Neste âmbito construir um currículo que esteja permeado de valores democráticos ao invés de tecnocráticos é essencial para fomentarmos um processo de ensino que possibilite aos educandos entenderem o mundo a sua volta. Essa percepção é defendida por Santos (1992) no qual destaca que:

O ensino para o cidadão, através de CTS, deve concentrar-se no desenvolvimento da capacidade de tomada de decisão por meio de uma abordagem que inter-relacione ciência, tecnologia e sociedade concebendo a primeira como processo social, histórico e não dogmático (SANTOS, 1992, p. 138).

Esses valores devem tornar mais significativo os conteúdos trabalhados em sala, construindo desta maneira uma sociedade em que as pessoas tenham amplo 
conhecimento acerca das questões científicas e tecnológicas. Essa função fica a cargo do processo educativo, haja vista, que o seu propósito é ajudar os educandos a compreenderem que os valores democráticos e socioambientais são de suma importância para a sociedade.

Auler (2007) é defensor de uma educação que privilegie os postulados do enfoque CTS, pois esse tem como meta estimular os alunos a conhecer e entender o desenvolvimento técnico e científico e seus impactos na sociedade e meio ambiente. Contudo, devemos ter consciência que o processo de ensino de ciências baseados na perspectiva CTS ainda carece de estratégias metodológicas e materiais didáticos que possibilitem a implementação de forma efetiva dos conceitos e ideais postulados por esta linha de pensamento. Ainda que existam iniciativas pontuais nesse sentido como o trabalho de Oliveira, Assis e Travain (2019). Diante desta constatação desenvolvemos uma estratégia metodológica que tem por base o uso do RPG como elemento catalizador para o ensino de Ciências e Geografia tendo como foco os estudos sobre CTS.

\section{O RPG COMO ESTRATÉGIA METODOLÓGICA:}

Diante dessas efervescentes mudanças e a busca por novas metodologias, o RPG surge como um elemento que pode contribuir para ocupar a lacuna aberta deixada por metodologias de ensino inertes e ineficientes. As suas características são pertinentes para a sua utilização como estratégia metodológica.

A utilização do RPG como estratégia metodológica vem sendo utilizado com êxito no processo de ensino e aprendizagem nas áreas de História, Matemática, Física, Biologia, etc, como sinaliza Pavão (2000), Marcatto (1996) e Rocha (2006).

A relevância da utilização dessa modalidade de jogo como ferramenta didáticopedagógica, advém do seu caráter lúdico e envolvente, em que os alunos passam a vivenciar o conteúdo a partir da jornada ou campanha ${ }^{1}$, o que acaba gerando uma maior identificação dos discentes com a temática abordada. Outro fator relevante em relação ao uso do RPG como estratégia metodológica são as situações problemas geradas ao longo da jornada que permitem aos discentes a superação de desafios que lhe são

\footnotetext{
1“'Denominação dada a cada partida ou rodada de um jogo de RPG, sendo que jornada para uma partida de curta duração e campanha para uma partida que pode durar dias, meses ou anos." Jackson (1994).
}

Recebido em: $1 \% 04 / 2020$

Aceito em: 15/09/2020 
impostos, cuja tal ação exige raciocínio, pensamento rápido, ideias coletivas, elementos que caracterizam o processo de ensino e aprendizagem.

Devido a essa série de pontos positivos, o RPG surge como uma estratégia metodológica que minimiza o gargalo existente no processo de ensino e aprendizagem principalmente no ensino de ciências, tendo em vista as dificuldades que os professores destas áreas têm em adequar e implementar novas estratégias metodológicas. De acordo com Marcatto (1996, p.12):

No RPG o jogador não é um mero espectador, mas um participante ativo que, como um ator, representa um papel e, como um roteirista, escolhe caminhos e toma decisões, nem sempre previstas pelo mestre, contribuindo na recriação da aventura.

Nesta perspectiva, o jogo possibilita o desenvolvimento cognitivo, a criatividade, estimula a pesquisa, melhora a convivência em grupo, ou seja, gera um maior nível de aprendizagem nos alunos. Uma das maiores contribuições do RPG para o ensino e aprendizagem está na possibilidade de discutir temas do cotidiano e que essa discussão permita um crescimento individual dos jogadores/alunos através da experimentação de novas vivências coletivas, outro fato que merece destaque é que o jogo permite uma maior autonomia, em que este deixa de ser apenas um agente receptor passando agir diretamente no seu processo formativo. Tendo como foco essas perspectivas propomos o uso do RPG "EPIDEMIA" como estratégia metodológica para o ensino de Ciências e Geografia dentro de enfoque CTS. É importante salientarmos que os estudos CTS são alicerçados e baseados na cooperação entre as diferentes áreas do conhecimento, abarcando uma variedade de ideias com o propósito de oferecer aos educandos uma visão mais ampla acerca de C\&T, permitindo assim construírem argumentos que englobe conceitos, argumentos e ideias variadas; levando-se em conta essas questões fica nítido que o ensino CTS é interdisciplinar, pois a construção dos conceitos e ideias são formados de maneira conjunta entre as diferentes áreas do conhecimento.

Fazenda (1994, p. 83), explica que a interdisciplinaridade é “ [...] uma relação de reciprocidade, de mutualidade, ou melhor, dizendo, um regime de copropriedade que iria possibilitar o diálogo entre os interessados. Neste sentido, pode dizer-se que a interdisciplinaridade depende de uma atitude". Esse raciocínio se enquadra perfeitamente com ensino CTS, Duso e Borges (2001, p.399) descrevem que: 
a interdisciplinaridade, no ensino de ciências, é coerente com o enfoque em ciência, tecnologia e sociedade (CTS), que busca desenvolver a racionalidade e a participação significativa do estudante no seu meio social.

Em razão desta característica, compreendemos que o ensino baseado na perspectiva CTS possibilita os estudantes, desenvolverem sua autonomia, construir uma linha de pensamento crítico sobre a ciência, a tecnologia e a sociedade. De maneira geral, essas ideias permitem criar condições para que os estudantes possam construir seus próprios argumentos em relação aos diferentes elementos que constituem a sociedade, está que engloba questões sociais, ambientais, econômicas e políticas.

\subsection{O RPG “EPIDEMIA” E SUA SEQUÊNCIA DIDÁTICA.}

A princípio é importante responder o seguinte questionamento: Por que estamos utilizando o RPG "EPIDEMIA" como estratégia metodológica no ensino de ciências e geografia? A resposta a esse questionamento é simples, o referente jogo trata de uma temática bastante pertinente, envolvente e atual, pois enquadra questões sobre vacinas, vírus, biologia, contaminação e recursos hídricos, etc. O jogo é ambientado em uma cidadezinha que foi infectada por um vírus mortal e agentes do governo devem descobrir o que está acontecendo e como esse vírus se espalhou contaminando os habitantes da cidadezinha. Com base no desfecho da história narrada neste RPG podemos desenvolver uma série de discussões sobre Ciência, Tecnologia e Sociedade, permitindo aos professores desenvolver e construir juntos aos estudantes concepções e forjar opiniões, bem como discutir diferentes visões sobre C\&T, a fim de reforçar o debate feito pelo movimento CTS.

De acordo com Amaral (2003, p.49) cada disciplina envolvida no jogo tem objetivos específicos para sua área, assim como também objetivos e metas comuns como podemos vislumbrar a seguir:

Ao utilizamos essa história como pano de fundo para apresentar aos alunos as questões ligadas à disseminação de vírus e a Ética na Ciência, utilizando conteúdos de Biologia, Geografia, Física e Matemática.

É importante salientar descreve o papel de cada disciplina envolvida na atividade.

Em Geografia, são trabalhados aspectos do relevo e clima, além das alterações ambientais produzidas pelo homem.

Recebido em: $1 \% 04 / 2020$

Aceito em: 15/09/2020 
Em Física, a construção de instrumentos ópticos e alguns tópicos de Cinemática.

Em Matemática, as relações de probabilidade e estimativas a partir equações exponenciais, no que se refere à disseminação de uma doença entre os habitantes de uma localidade.

Em Biologia, as particularidades dos vírus e consequências do contato com o organismo humano, sistema imunológico, sistema nervoso e das epidemias.

Para a execução desta estratégia metodológica são necessárias algumas orientações: como este deve ser operacionalizado em sala de aula e critérios que devem ser levados em consideração:

\section{$\left.1^{\circ}\right)$ Quantidade de alunos/personagens.}

O jogo de RPG deve ter um número mínimo de participante, embora os manuais clássicos não estabeleçam nenhuma regra rígida sobre o número de jogadores; entretanto, na sala de aula o ideal é que se tenha um número reduzido de participantes para facilitar a coordenação do trabalho pelo professor.

\section{$2^{\circ}$ ) Condução da atividade.}

Cada aluno do grupo será o participante ativo numa rodada de jogo, de maneira que, ao final, todos os alunos da equipe tenham tomado uma atitude em relação ao seu personagem. Nesta etapa da atividade é crucial que os alunos prestem atenção nas falas dos demais colegas/personagens para se posicionar em relação a situação descrita e narrada pelo outro.

\section{$\left.3^{\circ}\right)$ Duração da Atividade}

Como em média o tempo de duração de uma aula é de 45 minutos o ideal é desenvolver a atividade em duas aulas, se a temática for extensa é interessante que o jogo seja divido em jornada, sendo que cada jornada tenha uma duração máxima de duas aulas.

Durante a aventura alguns pontos podem ser levantados pelo professor com o intuito de fomentar as discussões que estão sendo conduzidas, a fim de complementar a aprendizagem dos alunos envolvidos na aventura. Neste sentido, o professor deve sugerir alguns desafios para serem superados pelos alunos podendo ser na forma de perguntas.

Além dos questionamentos e discussões proporcionados pelo RPG, podemos utilizar em conjunto a sequência didática desenvolvida por (MACEDO et al, 2019) a 
fim de ampliar e maximizar o aprendizado dos alunos. Sendo que a sequência didática pode ser condensada pelo seguinte esquema (figura 01: Sequência didática).

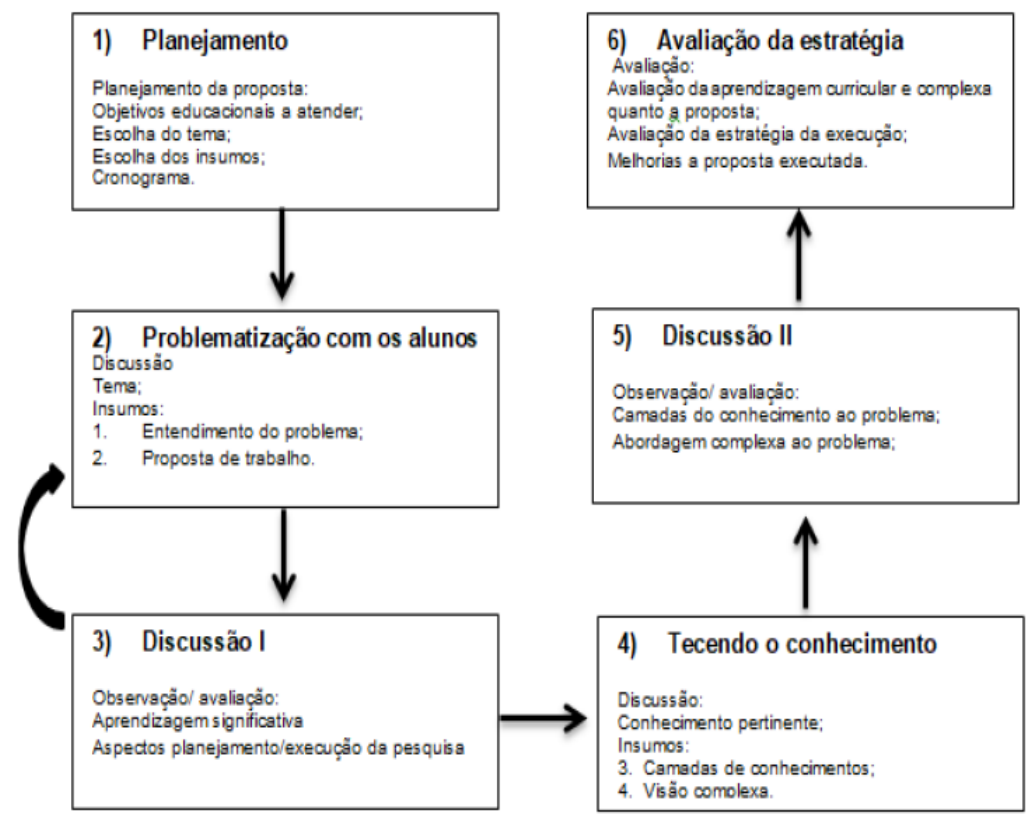

Figura 01- Sequência didática

Fonte: Elaborado por Macedo et al, (2019)

Ao refletirmos sobre essa estratégia metodológica fica evidente que esta pode proporcionar um ensino e aprendizagem de qualidade respeitando as suas limitações. Isso posto, devemos ter em mente que a utilização do RPG como estratégia metodológica não será a tábua de salvação do processo de ensino e aprendizagem, mas tem muito a contribuir com a formação dos alunos e facilitar de maneira plausível o trabalho dos professores em sala de aula. Outro ponto que devemos levar em consideração é que essa estratégia metodológica e a sequência didática desenvolvida por Macedo (2019) tem como característica principal transformar o pensamento dos estudantes, fornecendo-lhes a oportunidade de uma aprendizagem significativa na qual eles têm uma participação expressiva no seu processo formativo, isso se deve pelo fato de que com essa metodologia os estudantes deixam de ser meros expectadores, receptores e passarão a se protagonistas da sua formação educacional superando as amarras de um ensino tradicional que tem suas bases alicerçadas no enciclopedismo e na memorização, excluindo do seu processo educacional uma formação crítica e holística acerca do problemas sociais, ambientais, políticos e científicos.

\section{CONCLUSÃO:}

Recebido em: $1 \% / 04 / 2020$

Aceito em: 15/09/2020 
A estratégia metodológica que estamos propondo com base na utilização do RPG "EPIDEMIA" como elemento catalizador, tem grande potencial para o ensino interdisciplinar e com enfoque CTS, haja vista que a sua execução possibilita aos alunos construírem de maneira coletiva o seu conhecimento e entender forma holística o papel da ciência e tecnologia perante a sociedade. É importante salientarmos que a forma como essa proposta é executada irá permitir o desenvolvimento de uma aula dinâmica e interativa em que os alunos envolvidos terão a oportunidade de desenvolver um maior interesse em relação as questões que envolvem ciência, tecnologia e sociedade. Para que isso seja possível se faz necessário seguir de forma correta as orientações descritas anteriormente no texto. Todavia, isso não se trata de um manual, mas de um experimento que pode ser moldado de acordo com as condições presentes na escola. Outro aspecto importante é que essa estratégia metodológica pode ser executada em sala, independente das condições físicas e estruturais da escola.

Por fim, dois pontos devem ser esclarecidos, primeiro essa estratégia metodológica ainda não foi testada em sala de aula; o outro ponto é que temos ciência do seu potencial, haja vista que em outras disciplinas a utilização do RPG como suporte pedagógico veem obtendo relativo sucesso.

\section{REFERÊNCIAS:}

AMARAL, Ricardo Ribeiro do. RPG na escola: aventuras pedagógicas. Recife : Ed. Universitária da UFPE, 2013.

AULER, Décio. Enfoque ciência-tecnologia-sociedade: pressupostos para o contexto Brasileiro. Ciência \& Ensino, vol. 1, número especial, novembro de 2007.

AULER, Décio; BAZZO, Walter Antonio. Reflexões para a implementação do movimento CTS no contexto educacional brasileiro. Ciência \& Educação, v.7, n.1, p.113, 2001. Disponível em: http://www.scielo.br/scielo. Acesso em: 29. Nov. 2019.

BAZZO, Walter Antonio. Ciência, Tecnologia e Sociedade: e o contexto da educação tecnológica. 4.ed.Florianópolis: Ed. da UFCS, 2014,

BERNARDO, José Roberto Rocha; VIANNA, Deise Miranda; SILVA, Vitor Hugo Duarte da. A construção de propostas de ensino em Ciências-Tecnologia-Sociedade (CTS) para abordagem de temas sociocientíficos In: SANTOS, Wildson Luis Pereira dos, e AULER, Décio (org). CTS e educação cientifica: desafios tendências e resultados de pesquisas. Brasília: editora Universidade de Brasília, 2011. p. 373-393.

Recebido em: $1 \% 04 / 2020$

Aceito em: 15/09/2020 
CEREZO, J. A. L., Ciencia, Tecnología y Sociedad: el estado de la cuestión en Europa y Estados Unidos, Revista Iberoamericana de Educación. n n 18, 1998.

DUSO, Leandro; BORGES, Regina Maria Rabelo. Projetos integrados em sala de aula: ressignificação do processo de aprendizagem por meio de uma abordagem CTS In: SANTOS, Wildson Luis Pereira dos, e AULER, Décio (org). CTS e educação cientifica: desafios tendências e resultados de pesquisas. Brasília: editora Universidade de Brasília, 2011. p. 395-416.

FAZENDA, Ivani Catarina Arantes. Interdisciplinaridade: história, teoria e pesquisa. 4. ed. Campinas: Papirus, 1994.

JACKSON, Steve. Mini Gurps: regras básicas para jogar RPG 2. ed. São Paulo: Devir, 1994.

JAPIASSU, Hilton. Interdisciplinaridade e patologia do saber. Rio de Janeiro: Imago, 1976.

GARCÍA, M. I. G., LÓPEZ CEREZO, J. A., LUJAN, J. L. Ciencia, tecnología y sociedad: una introducción al estudio social de la ciencia y la tecnología. Madri: Tecnos, 1996.

MACEDO, Luiz Carlos Aires; MELLO, Débora Amaral Taveira; Neves, Marcos Cesar Danhoni. Uma proposta didática metodológica para se trabalhar CTS e complexidade de Morin. In: XII Encontro Nacional de Pesquisa em Educação em Ciências - XII ENPEC Universidade Federal do Rio Grande do Norte. Anais. Natal, RN, 2019. P.1-8.

MARCATTO, Alfeu. Saindo do quadro. São Paulo; A. Marcatto, 1996.

MEMBIELA, P. Uma revisión del movimiento CTS em La enseñanza de lãs Ciências. In:(org.). Enseñanza de las Ciências desde la perspectiva Ciência-TecnologíaSociedad: Formación científica para la ciudadanía. Madrid: Nancea, 2001.

NUNES, A. O. et al. Análise das relações ciência-tecnologia-sociedade em livros didáticos de química geral. Revista Areté | Revista Amazônica de Ensino de Ciências, [S.1.], v. 13, n. 27, p. 26-37, jul. 2020.

NUNES, Albino Oliveira. Possibilidades de enfoque CTS para o ensino superior de química: proposta de uma abordagem para ácidos e bases Natal/RN, Universidade Federal do Rio Grande do Norte, UFRN, 2014. 240p. Tese de Doutorado.

OLIVEIRA, M. C.; ASSIS, A.; TRAVAIN, S. Doenças Negligenciadas: proposta de uma sequência didática pautada no enfoque CTS. Revista Insignare Scientia - RIS, v. 2, n. 4, p. 332-348, 19 dez. 2019.

PAVÃO, Andreá. A aventura da leitura e da escrita entre mestres de Roleplaying Game. 2.ed. São Paulo: Devir, 2000.

Recebido em: 1\%04/2020

Aceito em: 15/09/2020 
ROCHA, Mateus Souza. RPG: jogo e conhecimento. Dissertação (Mestrado em Educação) - Universidade Metodista de Piracicaba. Piracicaba: UNIMEP, 2006. Disponível em: https://www.unimep.br/phpg/bibdig/pdfs/2006/WABULJNKJFJJ.pdf. Acesso em: 06 maio. 2019.

ROSA, S. E.; STRIEDER, R. Dimensões da democratização da ciência-tecnologia no âmbito da educação CTS. Revista Insignare Scientia - RIS, v. 1, n. 2, 24 ago. 2018.

SANTOS, W. L. P. O ensino de química para formar o cidadão: principais características e condições para sua implantação na escola secundária brasileira. Dissertação de Mestrado. Campinas: UNICAMP, 1992.

SANTOS, W. L. P. dos. Educação científica na perspectiva de letramento como prática social: funções, princípios e desafios. Revista Brasileira de Educação, Rio de Janeiro, v.12, n. 36, p. 474-492, set./dez. 2007.

SANTOS, W. L. P.; MORTIMER, E. F. Uma análise de pressupostos teóricos da abordagem C-T-S (Ciência - Tecnologia -Sociedade) no contexto da educação brasileira. Revista Ensaio, Belo Horizonte, v.02, n.02, p.110-132, jul-dez. 2000.

STRIEDER, R. B. Abordagens CTS na educação científica no Brasil: sentidos e perspectivas. 2012. Tese (Doutorado em Ensino de Física) - Ensino de Ciências (Física, Química e Biologia), Universidade de São Paulo, São Paulo, 2012. Disponível em: <http://www.teses.usp.br/teses/disponiveis/81/81131/tde-13062012-112417/>. Acesso em: 2013-10-15.

Recebido em: $1 \% 04 / 2020$

Aceito em: 15/09/2020 